\title{
Development of visual acuity in Rhesus monkeys deprived of patterned light during early infancy'
}

\author{
Austin H. Riesen,2 Robert L. Ramsey, ${ }^{2}$ and Paul D. Wilson ${ }^{3}$ \\ UNIVERSITY OF CHICAGO
}

\begin{abstract}
Abstraet Six monkeys given diffused light from birth to 20 or from birth to 60 days of age were found to have low visual acuity when first tested at these ages. With experience in patterned light their acuities improved consistently and at a rate comparable to that of normally reared monkeys.
\end{abstract}

Problem Whether the development of visual acuity is dependent only on maturational processes intrinsic to the growing organism, or whether photic stimulation of the maturing visual system is also needed, is a question of interest in many areas of inquiry. The present experiment was an exploration of this question with rhesus monkeys which were deprived of patterned light during early infancy for the purposes of another experiment (Wilson, 1964). While they accrued patterned light in limited daily increments, their visual acuities were measured by the width of striations needed to elicit optokinetic nystagmus. Early use of this measure has been reviewed by Riesen (1960a), and similar measurements made on normally reared infant rhesus monkeys have been reported by Ordy et al., (1962).

Subjects The subjects of this experiment were six infant rhesus monkeys born in the laboratory. They were separated from their mothers between 24 and $48 \mathrm{hr}$. after birth and were hand raised on a milk formula. Their birth weights ranged from 425 to $485 \mathrm{gm}$.

Apparatus An optokinetic apparatus was constructed similar to that described by Gorman et al., (1957), with the substitution of a motor drive for a hand drive. White shelf paper, 18 in wide, was striped at 1 in intervals with sets of striations formed by black tape, 1 , $1 / 2,1 / 4,1 / 8,1 / 16,1 / 32$, and $1 / 64$ in wide. One width was continued for 48 in along the paper and a nonstriated space was left between each set of equal-width stripes. The striated paper was moved across an arched bridge formed of clear, plastic, and the arched field was illuminated from below by four $25 \mathrm{w}$ tubular incandescent lamps, two on each side.

Procedure The Ss were placed in a darkroom a few hours after birth and dark-rearing was continued throughout the course of the experiment. The total neonatal exposure to patterned light was 1 to $2 \mathrm{hr}$. for four of the Ss, $7 \mathrm{hr}$. for Bess, and $9 \mathrm{hr}$. for the sixth S, April. In the initial weeks, the animals were given daily diffused light exposures, accruing between 18 and $48 \mathrm{hr}$. ( $24 \mathrm{hr}$. median) of diffused light per ten-day period. This was provided by bringing the Ss into the light with their eyes covered by ocular contacts made of thin white plastic. A similar method has been used by Mishkin et al., (1959) and by Ganz and Riesen (1962). When three Ss were 20 days old, and the other three were 60 days old, the diffused light experience was ended and the Ss were provided $1 / 2 \mathrm{hr}$. periods of patterned light, five times daily. In this way, $2.5 \mathrm{hr}$. of unrestricted patterned light was accrued daily. Beginning with the first day of patterned light exposure and continuing during the daily periods in the light, tests were made of the Ss' visual capacities.

To obtain an optokinetic index of visual acuity, the Ss were restrained in a horizontal position with the face either 10 in or 14 in below the midpoint of the arched test field. The arched field had a 12 in radius. While the rate at which the striations were moved was varied purposely, the typical angular velocity was about 10 degrees per sec. with movement from both left to right, and right to left across the S's visual field. Stripes of greater width were tried first, and then successively narrower stripes were used until no optokinetic nystagmus was observed. The series was then presented in reverse. Two Os participated in each test session.

Results The numbers of hours of patterned light experience preceding manifested visual resolution of 4 min. or better, were $1.5,5.5$, and $43 \mathrm{hr}$. in the 20-Day Group, and 15.5, 66.0, and 71.0 hr. in the 60-Day Group. Two Ss in the 60-Day Group, Bess and Ditto, were difficult to test, because they frequently shut their eyes, or averted their gaze from the test field. This may have distorted their measured visual acuities in the direction of higher thresholds, yet Ditto exhibited a visual acuity of $4 \mathrm{~min}$. within one week of patterned light exposures. The third $S$ in the 60-Day Group, April, had accrued some $50 \mathrm{hr}$. of patterned light experience before the apparatus was ready to use, but the consistencies of April's responses suggest that the data obtained from this $\mathrm{S}$ are reliable. Initial threshold was $43 \mathrm{~min}$. of visual angle, and this improved gradually during $20 \mathrm{hr}$. (by 89 days of age) to $4 \mathrm{~min}$. Similarly, the responses of the three 20Day Ss, when they were subjected to repeated testing (see Fig. 1), showed high intra-subject reliability, although there were marked differences between Ss. The rate of improvement in visual acuity varied considerably among the individual $\mathrm{Ss}$, but each $\mathrm{S}$ responded to stripes subtending $4 \mathrm{~min}$. of visual angle before 30 days with limited daily patterned light experience. The progress of the three 20-Day Ss is graphically compared in Fig. 1 with the progress of four infant rhesus having normal visual experience, as reported by Ordy et al., (1962). It should be noted that the Ss of that study were continuously in a lighted environment, while the Ss of this experiment were restricted to $2.5 \mathrm{hr}$. of light per day. 


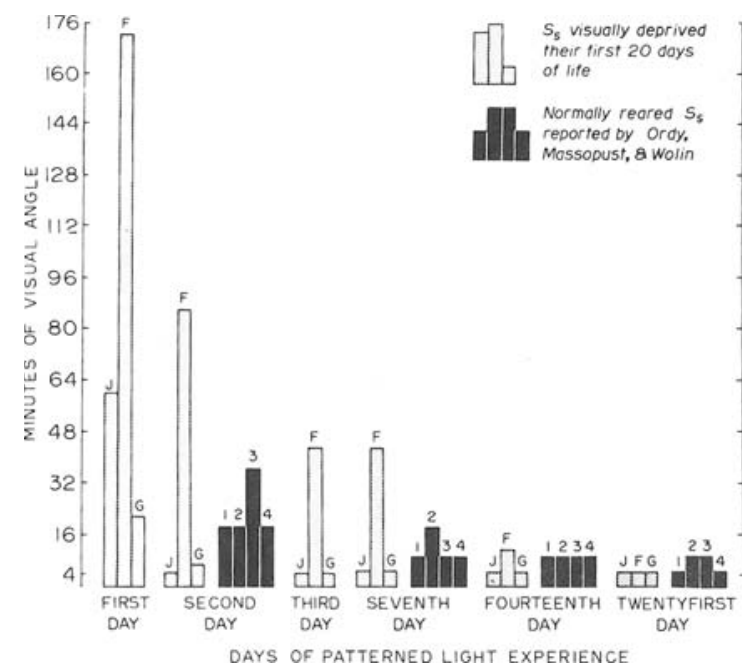

Fig. 1. The development of visual acuity in rhesus monkeys after an initial 20 days with patterned light deprivation and in normally reared rhesus infants, reported by Ordy, Massopust, \& Wolin (1962).

These data can be supplemented by observations on the same Ss made by one of the authors in conjunction with other experiments (Wilson, 1964). Pupillary constriction was typically observed when the monkeys were first brought into patterned light, although in two Ss the consensual pupillary response was delayed until the second day. The number of days of patterned light exposures preceding observed ocular pursuit of a moving light source (1-3 days) and ocular pursuit of a moving object (4-12 days) compares quite favorably with the days of age at which these behaviors are reported to appear in normally reared rhesus (Hines, 1942; Mowbray \& Cadell, 1962). Visual placing responses were elicited in 7 to 12 days, and avoidance of apparent depth on the Gibson and Walk visual cliff was obtained in 11 to 20 days, yet no animal responded with an eyeblink to a threatened poke to the eye within 30 days of patterned light exposure.

\section{Discussion The small size of the sample and the} extent of individual differences limits the conclusions which can be drawn from this study, yet certain consistencies are apparent in the data. After early deprivation of patterned light, the monkeys initially had poor visual acuity; however, the data give no indication that early patterned light deprivation prevents the rhesus monkey from attaining normal visual acuity when patterned light experience is provided again. Riesen's (1960b) results with chimpanzees suggests this may be less true for animals long deprived of diffused light as well as patterned light stimulation. The Ss in this experiment with only 2.5 hr. of patterned light daily attained within 1 to 30 days a visual acuity comparable to that attained by normally reared monkeys in 15 to 30 days of continuous light from birth (Ordy et al., 1962). This suggests that the interaction between the maturation of the visual system and the use of that system in patterned light maybe more effective for visual development in the 20 day old rhesus, than it is in the newly born animal. This may not be true for animals older than 20 to 30 days. The present data are insufficient to define the effects of 60 days or more without patterned light stimulation relative to the effects of 20 days or less of similar deprivation. There is need also of determining possible effects of the daily use of our contact diffusers on corneal curvature.

The rapidity of development of visual acuity in three Ss contrasts strikingly with the slower development of such visually guided behaviors as visual placing, avoidance of apparent depth on the visual cliff, and a reach of the hand, even inaccurately, to a visual stimulus. This points to the necessity of prolonged visual experience, as well as a sufficient neuromuscular maturation, for these kinds of visually guided behaviors in the rhesus monkey. This conclusion is consistent with the protracted learning of visual pattern discriminations by dark-reared chimpanzees, reported by Riesen $(1947,1950)$. In general, however, caution must be exercised in extending these conclusions to other species, in view of the phyletic differences in perceptual development demonstrated by such studies as those of Walk and Gibson (1961).

\section{Referenees}

GANZ, L., \& RIESEN, A. H. Stimulus generalization to hue in the dark-reared rhesus monkey. J.comp. physiol. Psychol., 1962, 55, 92-99.

GORMAN, J. J., COGAN, D. G., \& GELLIS, S. S. An apparatus for grading the visual acuity of infants on the basis of optokinetic nystagmus. Pediatrics, 1957, 19, 1088-1092.

HINES, M. The development and regression of reflexes, postures, and progression in the young macaque. Carnegie Inst. Wash. Contrib. Embryol., 1942, 30, No. 196, 153-209.

MISHKIN, M., GUNKEL, R. D., \& ROSVOLD, H. E. Contact occluders: a method for restricting vision in animals. Science, 1959, 129, 1220 . MOWBRAY, J. B., \& CADELL, T. E. Early behavior patterns in rhesus monkeys. J. comp. physiol. Psychol., 1962, 55, 350-357.

ORDY, J. M., MASSOPUST, L. C., \& WOLIN, L. R. Postnatal development of the retina, ERG, and acuity in the rhesis monkey. Exp. Neurol. , 1962, 5, 364-382.

RIESEN, A. H. The development of visual perception in man and chimpanzee. Science, 1947, 106, 107-108.

RIESEN, A. H. Receptor functions. In Mussen, P. H. (Ed.) Handbook of research methods in child psychology. New York: Wiley, 1960a. RIESEN, A. H. Brain and behavior: Symposium 4. Effects of stimulus deprivation on the development and atrophy of the visual sensory system. Amer. J. Orthopsychiat., 1960b, 30, 23-36.

WALK, R. D., \& GIBSON, E. J. A comparative and analytical study of visual depth perception. Psychol. Monogr., 1961, 75, No.15, 1-44. WILSON, P. D. Unpublished research for $\mathrm{Ph}$. D. dissertation at the University of Chicago.

\section{Notes}

1. This investigation was supported by research grant No. B-1590 from the National Institute of Neurological Diseases and Blindness, National Institutes of Health, U. S. Public Health Service.

2. Present address: Department of Psychology, University of California, Riverside, California, 92502.

3. Present address: Center for Brain Research, University of Rochester, Rochester, New York, 14627.

4. The ocular contacts were made of white translucent Tenite butyrate manufactured by Eastman Chemical Products, Inc., Kingsport, Tennessee. 